\title{
Ultrasonographic Diagnosis of Fetal Resorption in Relation to Age, Parity, Body Condition and Breed in Bitches
}

\author{
Lokesh Kumar Sharma, T. Sarath*, Cecilia Joseph, P. Sridevi, \\ N. Arunmozhi and G. Monica \\ Department of Clinics, Madras Veterinary College, Vepery, Chennai-07, Tamil Nadu \\ Veterinary and Animal Sciences University, Tamil Nadu, India \\ *Corresponding author
}

\section{A B S T R A C T}

Keywords

Canine, Ultrasonography,

Fetal resorption,

Incidence, Breed, Age,

Parity

Article Info

Accepted:

02 May 2018

Available Online:

10 June 2018
The influence of breed, age, size and parity of the bitches on the incidence of fetal resorption was analyzed in the present study. Nearly 56 percent of fetal resorption cases presented $(n=64)$ were either in Labrador retriever or German shepherd.17.18 per cent of all fetal resorption encountered was in brachycephalic breeds like Pug. The size of the breed was found to have a significant effect on the incidence of fetal resorption, the incidence being significantly higher in medium and large size breed. It was also observed that the incidence of the fetal resorption was highest in bitches aged 2-4 years and gradually declined with the advancing age. Bitches less than 4 years accounted for nearly 62 per cent of the fetal resorption cases suggesting the preference of owners to breed animals at their younger age and withhold breeding in aged animals. In the present study 37.50 percent of cases referred were primiparous and the rest had delivered 1-8 times. The incidence of fetal resorption decreased progressively with increase in parity and the least incidence was recorded in animals with more than 5 previous deliveries.

\section{Introduction}

The use of ultrasonography in bitches in early days was confined only to the diagnosis of pregnancy. Nowadays it is widely used for monitoring of fetal development, gestational age, predicting parturition etc.

Further, it also used for diagnosis and management of reproductive tract diseases including fetal abortion and resorption in small animals. In recent years, advances in canine reproduction have facilitated pregnancy management to clinical service that has application from the beginning to the end of gestation (Concannon and Verstegen, 1998). Studies on factors influencing the incidence of fetal resorption would help a veterinarian to identify animals most commonly predisposed for dystocia and fetal resorption and decide on the course of action to prevent dystocia and reduce the maternal and fetal mortality. Pregnancy loss may occur at any stage of gestation in the bitches and may be manifested by embryonic death and resorption, abortion of alive or dead fetus, still born pups or fetal mummification and retention in dam's uterus or peritoneal cavity beyond the normal time of 
parturition (England, 1992). Resorption is defined as early embryonic or fetal death within the first 45 days of pregnancy (Johnston et al., 2001). When a resorption occurs in a bitch, there is absence of external signs. There are no contractions and the fetus is not being expelled out. The bitch essentially dissolves the fetus in the uterus. Most scientific studies have reported that $10-15 \%$ of fetuses are resorbed and has no externally visible signs.

Fetal resorption occurs because of infectious and non-infectious causes. Infectious causes include bacteria, parasites and viruses. Some bacterial organisms that causes resorption include Brucella canis, Campylobacter, Salmonella, E. coli and B-hemolytic Streptococci and parasites include Toxoplasma gondii and Neospora caninum and viral causes include Canine Herpesvirus, Canine Parvovirus Type 1, Canine Distemper Virus, Mycoplasma and Ureaplasma (Ortega, 2006). The non-infectious causes of resorption include endocrine abnormalities, drugs given to the bitch during pregnancy, genetic factors, environmental factors and nutritional factors. An endocrine abnormality that can cause resorption is hypoluteodism which may be due to insufficient secretion of progesterone by the corpora lutea during pregnancy (Gorlinger et al., 2004). The genetic factors include chromosome abnormalities, very tight inbreeding and the age of the bitch and environmental factors include summer stress due adverse climatic effect, metal levels in the water, trauma etc. (Johnston et al., 2001). Data on the incidence of fetal deaths followed by fetal resorption in the $\mathrm{dog}$ are scarce. Thus looking in to the magnitude of adverse effect on pregnancy, the present study has been designed with following objectives to determine the incidence of fetal resorption in the bitches and also to assess the association of fetal resorption in bitches with the age, size, breed, parity and season.

\section{Materials and Methods}

The ultrasonographic evaluation in the present study was performed in suspected cases of abortion and dystocia that were presented to Small animal Obstetrics and Gynecology unit of Madras Veterinary College Teaching Hospital, Chennai from September 2015 to June 2016. The influence of breed, size, age and parity of the dam on the incidence of fetal resorption in bitches $(n=64)$ was studied by analyzing the medical records of dystocia and abortion and bitches with no sign of parturition more than 64 days after mating which were presented at the Small Animal Obstetrics and Gynaecology unit of Madras, Veterinary College Teaching hospital, Chennai between September 2015 to June 2016 as well as from the data generated from clinical cases handled during the course of present study.

The pooled data generated from the clinical records of fetal resorption and abortion cases treated retrospectively as well as dystocia cases treated during the course of the present investigation were analyzed to study the influence of the age, parity, body condition and breed of the bitch on the incidence of fetal resorption.

\section{Results and Discussion}

In the present study, 8 different breeds were presented with the complaint of abortion and no sign of parturition after 62 days of mating (Table 1). Nearly 56 per cent of the patients presented were either Labrador retriever $(34.37 \%)$ or German shepherd $(21.80 \%)$. Fetal resorption in brachycephalic breeds like pugs (17.18 \%), Dachshund (6\%) and Doberman $(7.8 \%)$ were also encountered in a relatively high frequency. Of all fetal resorption cases presented, 4 per cent were in Cocker spaniel. The incidence of fetal resorption was least in Dalmatian breed. 


\section{Ultrasonography of fetal resorption}

Serial ultrasonographical evaluation of fetal resorption demonstrated with the beginning of feeble fetal heart rate and loss in the normal architecture including fetal fluids followed by absence of fetal viability and collapse of fetal tissues. Further, it proceeds with visualization of anechoic regions within the gestational sac and it turns to hypoechoic mass just like that of a postpartum uterine echotexture. As a gross, the ultrasonographical findings of fetal resorption include absence of a heartbeat, lack of fetal movement, reduced volume and increased echogenicity of fetal fluid, and accumulation of gas within the fetal stomach or generally, within the fetus or uterus (Fig. 1). Fetal gas should not be confused with artifacts produced by overlying intestine (England, 1998).

Table.1 Breed-wise distribution of canine fetal resorption cases reported ( $\mathrm{N}=64)$

\begin{tabular}{|c|c|c|}
\hline Breed & Number of Cases of Fetal Resorption & Incidence (\%) \\
\hline Labrador retriever & 22 & 34.3 \\
\hline German shepherd & 14 & 21.8 \\
\hline Pug & 11 & 17.18 \\
\hline Doberman & 5 & 7.8 \\
\hline Dachshund & 4 & 6 \\
\hline Cocker spaniel & 3 & 4 \\
\hline Dalmatian & 3 & 4 \\
\hline Lhasa apso & 1 & 0.03 \\
\hline Rottweiler & 1 & 0.03 \\
\hline Total & $\mathbf{6 4}$ & $\mathbf{1 0 0}$ \\
\hline
\end{tabular}

Table.2 Size-wise distribution of canine fetal resorption cases reported $(\mathrm{N}=64)$

\begin{tabular}{|c|c|c|}
\hline Size of breed & $\begin{array}{c}\text { Number of cases of fetal } \\
\text { abortion }\end{array}$ & Incidence (\%) \\
\hline Small (BW < 10 Kg) & 13 & 20.30 \\
\hline Medium (BW 10-25 kg) & 15 & 23.43 \\
\hline Large (BW 25 TO 45 Kg) & 29 & 45.31 \\
\hline Giant (BW 45Kg and above) & 07 & 10.93 \\
\hline Total & $\mathbf{6 4}$ & $\mathbf{1 0 0}$ \\
\hline
\end{tabular}

Table.3 Age-wise distribution of canine fetal resorption case reported $(\mathrm{N}=36)$

\begin{tabular}{|c|c|c|}
\hline Age (years) & Number of cases of fetal resorption & Incidence (\%) \\
\hline$<2$ & 27 & 42.18 \\
\hline $2-4$ & 13 & 20.31 \\
\hline $4-6$ & 22 & 34.37 \\
\hline $6-8$ & 1 & 01.50 \\
\hline$>8$ & 1 & 01.50 \\
\hline Total & 64 & $\mathbf{1 0 0}$ \\
\hline
\end{tabular}


Table.4 Parity-wise distribution of fetal resorption cases treated $(\mathrm{N}=64)$

\begin{tabular}{|c|c|c|}
\hline Parity & $\begin{array}{c}\text { Number of cases of } \\
\text { Fetal resorption }\end{array}$ & Incidence (\%) \\
\hline $\mathbf{1 S t}$ & 24 & 37.50 \\
\hline $\mathbf{2 - 3}$ & 19 & 29.68 \\
\hline $\mathbf{4 - 5}$ & 18 & 28.12 \\
\hline $\mathbf{> 5}$ & 03 & 04.68 \\
\hline Total & $\mathbf{6 4}$ & $\mathbf{1 0 0 . 0 0}$ \\
\hline
\end{tabular}

Fig.1 Ultrasonographic view of fetal resorption

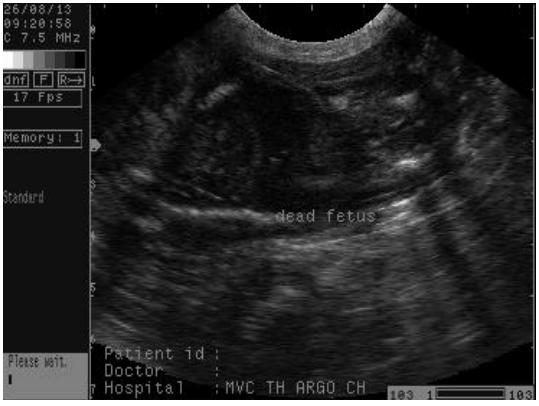

Fig1a.Presence of anechogenic areas with irregular fetal structures in a Labrador bitch

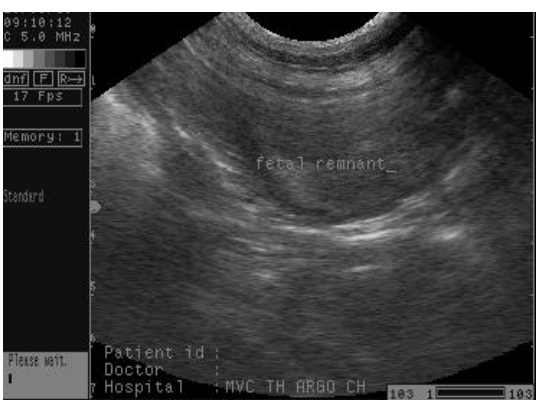

Fig1c.Presence of fetal remnants without any distinct fetal sac borders in a German shepherd bitch

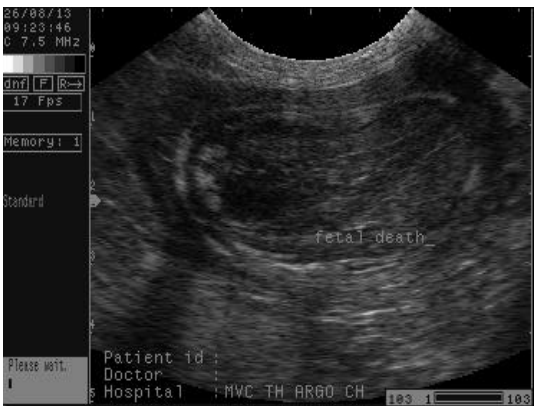

Fig1b.Presence of fetal sac without definite fetal structures in a Labrador bitch

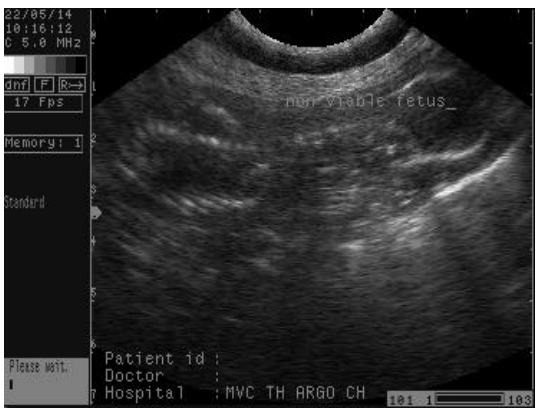

Fig1d.Presence of non-viable fetus with absence of heart beat in a pug

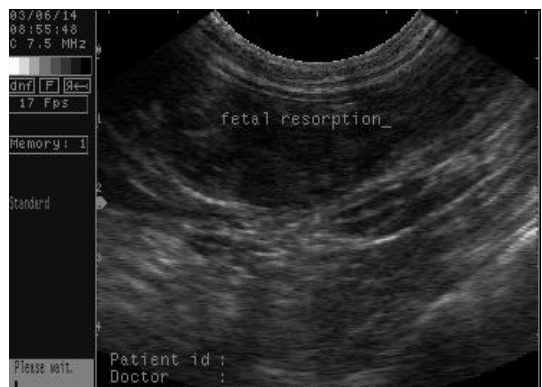

Fig1e.Presence of non-distinct fetal mass with empty fetal sacs in a Dachshund 


\section{Breed disposition}

The fetal resorption cases encountered in the present study 23.63 per cent were in brachycephalic breeds (Pug, Bull dog and Boxers). Brachycephalic breeds like Pugs and Bull dogs are being increasingly reared by dog owners and most canine breeders seem to be aware of a higher risk of dystocia in brachycephalic breeds. There is a wide consensus among obstetricians that boxers and other brachycephalic breeds are predisposed for dystocia. Factors suggested to be responsible for predisposition of brachycephalic breeds to dystocia include a slack abdominal musculature making it impossible to lift the fetus upto pelvic cavity (Bennett, 1980), a chord like structure crossing the lumen of the vagina ventrally just caudal to cervix (Smith, 1965) and peculiar shape of the fetal head making it difficult to enter the pelvic inlet (Arthur, 1975).

A higher frequency of fetal resorption was also encountered in Daschunds (8.40\%), Freak (1948), reported that Daschunds may show anatomically abnormal pelvis and are particularly prone for a particular type of primary uterine inertia. This observation appears to be substantiated by the results of the present study wherein nearly 75 per cent of dystocia cases in Dachshunds were due to primary uterine inertia, dystocias were recorded in only 4.20 per cent. There have been reports in the past about the low incidence of dystocia amongst mongrels (Darveild and Linde Forsberg, 1994).

The size of the breed was found to have a significant effect on the incidence of dystocia and fetal resorption in bitches, the incidence being significantly higher in medium and large sized breeds. Together, they accounted for nearly 56 per cent of dystocia cases presented for treatment (Table 2). Apparently, this observation may suggest that medium and large sized breeds are more prone for dystocia. The medium and large breeds were represented by 8 different breeds and these breeds also happen to be the preferred breeds among animal lovers and breeders in the city of Chennai and therefore the apparent higher incidence of dystocia in medium and large breeds may be more because of their higher population. On the other hand, Christiansen (1984) claimed that dystocia mainly occurred in miniature breed because their pups are relatively bigger as compared to the case in medium and large sized breeds.

\section{Age factor}

The frequency of fetal resorption in the present study was found to be highest in bitches aged less than four years and it gradually declined with the advancing age (Table 3). Bitches less than four years accounted for nearly 62 per cent of the dystocia cases. The observations made in the present study are similar to those of Gaudet (1985) and Darvelid and Forsberg (1994) who also recorded the highest incidence of dystocia in bitches aged 2-4 years and 2-3.5 years, respectively. The animals aged five years and above to be more prone for fetal resorption particularly due to uterine inertia.

The low occurrence of dystocia in animals aged 6 years and above, observed in the present study may probably be due to the fact that the most canine owners prefer not to breed aged animals. In the present study 37.5 per cent of the cases referred were primiparous and the rest had delivered 1-8 times. The incidence of fetal resorption decreased progressively with increase in parity and the least incidence was recorded in animals with more than 5 deliveries (Table 4). The results of the present study are in close conformity with those of Gaudet (1985) who reported the incidence of resorption in primiparus as 37.00 percent. 


\section{References}

Arthur, G.H. 1975. Maternal Dystocia. Veterinary Reproduction and Obstetrics, $4^{\text {th }}$ Edn., London Bailliere Tindall. Pp. 170-190.

Bennett, D. 1980. Normal and abnormal parturition. In: Current Therapy in Theriogenology: diagnosis, treatment and prevention of reproductive disease in animals. D. A. Morrow (Hrsg.). Philadelphia: W.B. Saunders Co. - S. 595-606.

Christiansen, I.J., 1984. Reproduction in the dog and cat. Bailliere Tindall, London., 197-221.

Concannon, P. and Verstegen J. 1998.Pregnancy in Dogs and Cats. In: Knobil E and Neil JN, eds. Encyclopedia of Reproduction. Vol. 3. New York: Academic Press. Pp: 145.

Darvelid, A.W. and Linde-Forsberg C. 1994. Dystocia in the bitch: A retrospective study of 182 cases. J. Small. Anim., Pract., 35: 402-407.

England, G.C., 1998. Ultrasonographic assessment of abnormal pregnancy. Veterinary Clinics: Small Animal Practice, 28(4), Pp. 849-868.

England, G.C.W and Russo, M. 2006. Ultrasonographic characteristics of early pregnancy failure in bitches. Theriogenology. 66: 1694-1698.

England, G.C.W.1992.Ultrasound evaluation of pregnancy and spontaneous embryonic resorption in the bitch. $J$ Small Anim Pract 33(9): 430-436.
Freak, M.J. 1948.The Whelping bitch.Vet. Rec., 60: 295-301.

Gary, C.W., England. 1998. Ultrasonographic Assessment of Abnormal Pregnancy. Vet Clin North Am Small Anim Pract. 28(4): 849-868.

Gaudet, A. D. 1985.Retrospective study of 128 cases of canine dystocia. $J \mathrm{Am}$ AnimHosp Assoc., 21: 813-818.

Gorlinger, S., Galac, S., Kooistra, H.S. and Okkens, A.C. 2005. Hypoluteoidism in a bitch.Theriogenology.64(1): 213-219.

Griffin, P.G. and Ginther, O.J. 1992. Research applications of ultrasonic imaging in reproductive biology. J.Anim. Sci., 70: 953-972.

Johnston, D.S., Root Kushtritz, M.V and Olson, P.N.S. 2001.Canine and feline Theriogenology. $1^{\text {st }}$ Ed., W.B. saunders, Company Philadelphia pp87.

Ortega, P. A., Rodrigue, B., Seguracorrea, J.C., Montes, J.C., A.R. and Jimenez, O.M. 2006. Prevalence of fetal resorption in stray dogs in Yucatan Mexico. J Small AnimPract. 47: 266269.

Rajamahendran, R., Ambrose, D.J. and Burton, B. 1994. Clinical and research applications of real time ultrasonography in bovine reproduction A review. Can. Vet. J., 35: 563-572.

Smith, K.W., 1965. Female Genital Tract. In: Canine Surgery. Edn.1 Archibald, J. editor, Santa Barbara, C.A. American Vet. Pub. Inc. pp 641- 676.

Sridevi, P., 2014. Ultrasonography of genital system in dogs. Raksha technical review. $1^{\text {st }}$ Ed. 27-30.

\section{How to cite this article:}

Lokesh Kumar Sharma, T. Sarath, Cecilia Joseph, P. Sridevi, N. Arunmozhi and Monica, G. 2018. Ultrasonographic Diagnosis of Fetal Resorption in Relation to Age, Parity, Body Condition and Breed in Bitches. Int.J.Curr.Microbiol.App.Sci. 7(06): 161-166. doi: https://doi.org/10.20546/ijcmas.2018.706.019 